SOUZA, I. I. . A diplomacia brasileira e a Guerra Civil Espanhola. In: Jose Carlos Sebe Bom Meihy. (Org.). Guerra Civil Espanhola 70 anos depois. São Paulo: EDUSP, 2011, v. 1, p. 139-156. ISBN: 978-85-314-1240-0

\title{
A diplomacia brasileira e a Guerra Civil Espanhola
}

\author{
Ismara Izepe de Souza ${ }^{1}$
}

Poucos acontecimentos internacionais despertaram no Brasil debates acalorados sobre ideologias políticas quanto a Guerra Civil Espanhola. Renomados artistas, intelectuais e personalidades políticas brasileiras não se furtaram a expor a sua percepção do conflito, quase sempre realizando analogias e comparações com a situação interna do país. A imprensa, responsável por informar sobre o cotidiano da guerra, dotou-se em grande parte de uma polarização que pouco refletia a complexidade do jogo de forças políticas presentes na Espanha.

A imagem da República espanhola como representativa dos ideais comunistas configurou-se em vários segmentos do governo brasileiro, estendendo-se também para a prática da Polícia Política. Houve, especialmente no período da Guerra Civil Espanhola, uma ampla repressão às associações e aos imigrantes espanhóis que se mobilizaram na tentativa de auxiliar, material ou moralmente, os republicanos na Espanha. ${ }^{2}$

Mesmo antes do conflito civil, alguns episódios deixaram evidentes as diferenças político-ideológicas entre o governo de Vargas no

\footnotetext{
${ }^{1}$ Mestre e doutoranda em História Social pela Universidade de São Paulo. É bolsista da Fundação de Amparo à Pesquisa do Estado de São Paulo e autora dos livros: República Espanhola: um modelo a ser evitado (São Paulo: Imprensa Oficial/Arquivo do Estado, 2001); Solidariedade Internacional. A comunidade espanhola do Estado de São Paulo e a polícia política diante da Guerra Civil da Espanha, 1936-1946 (São Paulo: Humanitas/FAPESP, 2005); Espanhóis: história e engajamento (Coleção Imigrantes no Brasil. São Paulo: Lazuli/Cia. Editora Nacional, 2006).

${ }^{2}$ Sobre a mobilização dos imigrantes espanhóis diante da Guerra Civil Espanhola ver: Ismara Izepe de Souza. Solidariedade Internacional, op.cit.
} 
Brasil e o da República da Espanha. A prisão de Luis Carlos Prestes após o movimento comunista de 1935 causou indignação em agremiações trabalhistas e estudantis espanholas, que chegaram a protestar e alvejar de tiros a Embaixada brasileira. Entre abril e maio de 1936, D. Leocádia, mãe de Prestes, liderou na Espanha uma intensa campanha em prol da libertação de seu filho sendo bem recebida, juntamente com sua filha Lygia, por vários setores da sociedade deste país. A amplitude que o movimento a favor da libertação de Prestes alcançou numa Espanha de intensas agitações políticas, pode ser verificada no fato de que tal campanha contou com o apoio de alguns dos mais importantes políticos ligados à República. Em um dos comícios realizados em prol do "cavaleiro da esperança" estiveram presentes Juan Casanovas, presidente do Parlamento Catalão e Dolores Ibárruri, deputada do Partido Comunista. Esta, também chamada de La Pasionaria, ficou conhecida mundialmente por sua atuação a favor da República da Espanha e por seus discursos memoráveis em defesa das Brigadas Internacionais.

Entre 1936 e 1939, a Espanha passou a ser um alvo maior de atenções da política externa brasileira. O Itamaraty demonstrou preocupação com os rumos dos acontecimentos espanhóis, uma vez que entendia que seus desdobramentos influenciariam a política internacional. Em agosto de 1936, como embaixador do Brasil em Washington, Oswaldo Aranha teceu considerações sobre o significado do conflito civil espanhol. Aranha considerava preocupante o apoio do México aos republicanos, efetivado através do envio de armas e munições. Valendo-se de um discurso maniqueísta considerava que:

... se vencerem as esquerdas espanholas, a offensiva communista e a bolchevisação dos países indo-espanhóis é uma ameaça a temer. Tenho razões para crer que já, agora, essas repúblicas estão soffrendo graves repercussões da lucta na Hespanha em sua vida interna e que a própria Argentina está sentindo esses effeitos. ${ }^{3}$

Apesar de analisar o conflito espanhol sob esta ótica, Oswaldo Aranha não coadunava com as opiniões do ministro das Relações Exteriores,

\footnotetext{
${ }^{3}$ Carta de Oswaldo Aranha para Getúlio Vargas. Washington, 26 ago. 1936. Arquivo Getúlio Vargas (GV c, 1936.08.26). CPDOC/FGV.
} 
José Carlos de Macedo Soares, que pretendia oferecer o apoio oficial brasileiro aos rebeldes espanhóis. ${ }^{4}$ Quando assumiu a direção do Itamaraty, em 1938, Oswaldo Aranha promoveu uma política cautelosa com relação à Espanha, transmitindo oficialmente seu apoio ao governo legalmente constituído naquele país. O governo brasileiro tentava praticar nos assuntos europeus uma política que estivesse afinada com os interesses norte-americanos, direcionando a política externa brasileira para uma ação coordenada com a dos demais países americanos, sob a liderança dos EUA.

A "neutralidade" brasileira não se consubstanciaria em atitudes louváveis. Em muitos momentos, a ação do Itamaraty pautou-se pelas desconfianças das diretrizes ideológicas que norteavam o governo republicano espanhol. Um documento presente no arquivo pessoal de Getúlio Vargas demonstra que o governo brasileiro realizou, sob sigilo, a doação de alimentos à zona nacionalista, poucos meses após a deflagração da guerra civil da Espanha. Essa seria mais uma prova da simpatia de Vargas aos revoltosos espanhóis que, se não podia ser expressa diretamente por conta dos compromissos brasileiros no cenário internacional, poderia se manifestar através de auxílio material. Em outubro de 1936, Francisco Franco escreveu a Getúlio Vargas agradecendo a doação de importantes quantidades de açúcar e café, comprometendo-se a manter a mais estrita reserva até que as circunstâncias permitissem dar publicidade ao gesto. ${ }^{5}$

Com o desencadear do conflito, tanto os consulados brasileiros quanto a Embaixada em Madri passaram a manter um estado de constante alerta e receio de que a onda de violência, presente em toda a Espanha, pudesse atingir os representantes diplomáticos brasileiros. Durante a maior parte de 1938 a representação diplomática brasileira ficou estabelecida em

\footnotetext{
${ }^{4}$ Vargas registrou em seus diários que no dia 10 de agosto de 1936 o ministro Macedo Soares o havia procurado com um cartapácio de informações sobre a Espanha propondo "uma manifestação do Brasil no sentido de definir-se a favor dos rebeldes, ou pelo reconhecimento da beligerância destes, ou por outro ato qualquer que tenha por objetivo uma quebra de neutralidade." No dia 17 do mesmo mês registrou que o ministro das Relações Exteriores continuava a insistir naquela questão. (Getúlio Vargas. Diário. São Paulo: Siciliano; Rio de Janeiro: FGV, 1995, p.531 e 534).

${ }^{5}$ Carta de Francisco Franco, "El jefe del Estado y general en jefe del Ejercito Nacional" para Getúlio Vargas. Salamanca, 29 out. 1936. Arquivo Getúlio Vargas (GV 36.10/1 XXIV - 44). CPDOC/FGV.
} 
Barcelona, sede do governo republicano espanhol desde outubro de $1937 .{ }^{6} \mathrm{Em}$ fevereiro de 1938, o embaixador brasileiro na Espanha, Alcebíades Peçanha, foi informado de sua aposentadoria compulsória, transferindo a chefia da missão para Carlos da Silveira Martins Ramos, que ficaria na capital catalã na qualidade de encarregado de negócios. ${ }^{7}$ Consideramos este último diplomata uma figura emblemática nos quadros do Itamaraty, pois foi o único que em suas análises sobre a questão espanhola, defendeu o governo legalmente constituído. ${ }^{8}$ Suas considerações acerca da Espanha em pleno conflito destoavam do teor dos documentos escritos por outros diplomatas, cujas críticas ao governo republicano eram exacerbadas e, por vezes, incompatíveis com a realidade.

Nos relatórios e ofícios assinados por Martins Ramos é perceptível sua comoção frente à situação das vítimas civis do conflito. Em novembro de 1938, este diplomata relatou ao Itamaraty que vinha auxiliando, em caráter particular, muitas crianças da cidade de Arenys del Mar. ${ }^{9}$ Nos jardins de sua residência, nesta cidade que fica próxima a Barcelona, eram oferecidos, duas vezes na semana, almoço e merenda para cem crianças selecionadas por sua esposa nas escolas públicas do local. Afirmou que o gesto teve grande repercussão, mas que infelizmente ele e sua mulher não conseguiam atender aos pedidos que chegavam diariamente de pais desejosos de verem seus filhos inseridos no grupo. ${ }^{10}$

Martins Ramos sugeriu que tal auxílio deixasse de ser particular e fosse realizado oficialmente pela representação brasileira. Argumentou que o Brasil poderia criar um "hogar brasileño" que estenderia o mesmo auxílio para 200 crianças, a exemplo da Suécia, que criara um Instituto que abrigava mais

\footnotetext{
${ }^{6}$ Em 31 de outubro, Juan Negrín anunciou a transferência do governo central para Barcelona. A Catalunha passou assim para o controle central. Hugh Thomas. A Guerra Civil Espanhola, $2^{\circ}$ vol. Rio de Janeiro: Civilização Brasileira, 1964, p.206.

${ }^{7}$ Telegrama do Ministério das Relações Exteriores para Consulado do Brasil em Barcelona. Rio de Janeiro, 05 fev. 1938. Lata 998, maço 16237. Arquivo Histórico do Itamaraty/RJ.

${ }^{8}$ Vasco Leitão da Cunha, diplomata atuante na Espanha na década de 1940, lembrou em suas memórias que Martins Ramos tinha uma postura de simpatia às idéias comunistas (Diplomacia em alto-mar, depoimento ao CPDOC. Rio de Janeiro: Fundação Getúlio Vargas, 1994, p.190).

${ }^{9}$ Referências ao auxílio oferecido por Martins Ramos às crianças de Arenys del Mar podem ser encontradas em: Jacint Aixer Bussalleu; Estanislau Torres. La guerra civil a Arenys del Mar. Publicacions de L'abadia de Montserrat, 1999, p.87.

${ }_{10}$ Ofício n. 110 de Carlos da Silveira Martins Ramos, encarregado de negócios do Brasil na Espanha para Oswaldo Aranha, ministro das Relações Exteriores. Barcelona, 01 nov. 1938. Lata 716, maço 10364. Arquivo Histórico do Itamaraty/RJ.
} 
de 500 delas. Não nos parece plausível a hipótese de que houve a anuência do governo brasileiro a tal proposta. O não rompimento com os republicanos servia à estratégia brasileira de manter distanciamento das questões européias, mas de forma alguma significava simpatias ou apoio aos legalistas. Sendo assim, acrescido o fato de tradicionalmente a Secretaria de Estado das Relações Exteriores alegar falta de verbas para solicitações que denotavam gastos extraordinários, era de se esperar a negativa do governo brasileiro para esta solicitação. Tal auxílio geraria gastos não previstos, além de consubstanciar o apoio brasileiro a um governo de "tendências esquerdistas".

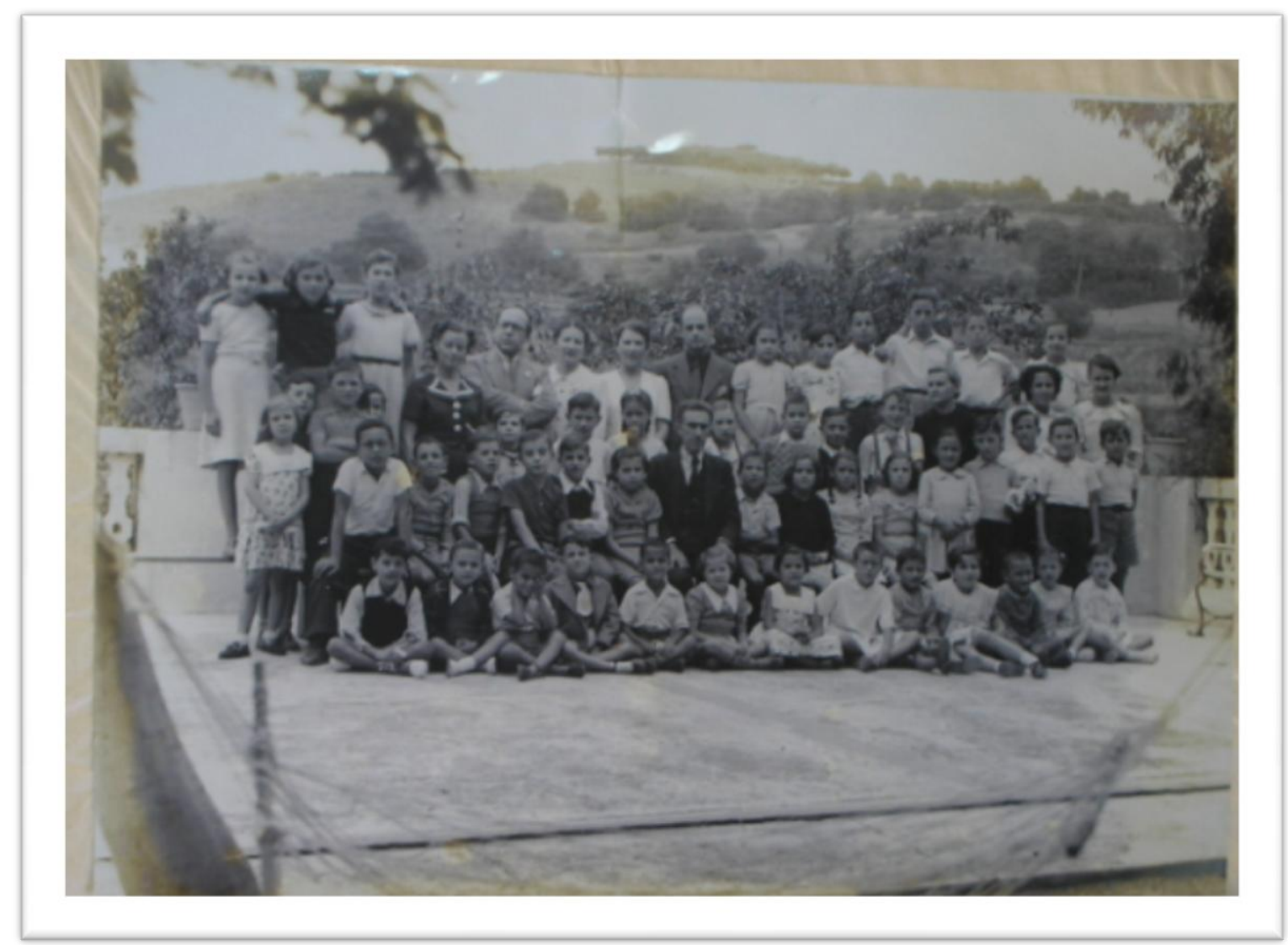

Grupo de crianças espanholas auxiliadas por Carlos da Silveira Martins Ramos. Fotografia anexada ao ofício n.110 de Carlos da Silveira Martins Ramos, encarregado de negócios do Brasil para Oswaldo Aranha, ministro das Relações Exteriores. Barcelona, 01 nov. 1938. Lata 716, maço 10364. Arquivo Histórico do Itamaraty/RJ. 
Pelo menos dois agentes consulares a serviço do governo brasileiro praticaram atividades relacionadas à defesa dos nacionalistas espanhóis. Adrian de Burgos, vice-cônsul na cidade de Almeria envolveu-se com a Falange e o movimento rebelde espanhol. ${ }^{11}$ Segundo a Embaixada do Brasil em Madri as autoridades desta cidade, durante o governo de Manuel Azaña, recebiam freqüentes queixas do comportamento hostil de Adrian que, mal visto pelos elementos da Frente Popular, foi detido logo no início do conflito. A situação do agente consular complicou-se após o governo republicano espanhol ter lhe retirado o exeqüator, ficando o mesmo sem imunidades diplomáticas. Alcebíades Peçanha informou ao Itamaraty que havia se esforçado nas negociações junto ao governo espanhol para amenizar a situação do referido agente, conseguindo que the fosse dado tratamento com "atenções especiaes" enquanto esteve detido. ${ }^{12}$

Adrian de Burgos faleceu em maio de 1937, e os documentos analisados nos permitem afirmar que sua morte está relacionada à sua prisão e ao contexto da guerra. É provável que tenha sido executado ou tenha morrido em decorrência dos maus-tratos e das condições precárias de carceragem. ${ }^{13}$ Em fevereiro de 1938, o embaixador Peçanha observou que Julio Morin, outro agente consular preso pelos republicanos espanhóis, poderia ter um destino "tão trágico" quanto o de Adrian. ${ }^{14}$

Desde o início do conflito, a Embaixada do Brasil ofereceu asilo àqueles que consideravam estar a sua segurança pessoal ameaçada pelos republicanos espanhóis. A magnitude e importância do asilo diplomático durante a contenda espanhola foi um ato, até então, sem precedentes na história das relações internacionais. A maior parte das representações

\footnotetext{
${ }^{11}$ De acordo com a nota (cópia) do governador civil de Almeria para Embaixada do Brasil na Espanha. Madri, 16 out. 1936. Missões Diplomáticas Brasileiras. Ofícios recebidos de Madri (janeiro de 1936 a julho de 1937). Arquivo Histórico do Itamaraty/RJ.

${ }^{2}$ Ofício n. 112 de Alcebíades Peçanha, embaixador do Brasil na Espanha para Mario de Pimentel Brandão, ministro interino das Relações Exteriores do Brasil. Madri, 31 dez. 1936. Missões Diplomáticas Brasileiras. Ofícios recebidos de Madri (1936 a junho de 1937). Arquivo Histórico do Itamaraty/RJ.

${ }^{13}$ Carta de Dolores de Burgos para Oswaldo Aranha, ministro das Relações Exteriores. Cádiz, 21 nov. 1939. Lata 1756, maço 35635. Arquivo Histórico do Itamaraty/RJ.

${ }^{14}$ Ofício n. 08 (secreto) de Alcebíades Peçanha, embaixador do Brasil na Espanha para Mario de Pimentel Brandão, ministro das Relações Exteriores do Brasil. Madri, 11 fev. 1938. Missões Diplomáticas Brasileiras. Ofícios recebidos de Madri (julho de 1937 a 1938). Arquivo Histórico do Itamaraty/RJ.
} 
estrangeiras sediadas em Madri, mais de trinta, praticou o asilo concedendo, segundo as estatísticas oficiais, refúgio a cerca de onze mil pessoas. ${ }^{15}$ Dos países latino-americanos, dois se destacaram pela amplitude na concessão de asilo: Chile e Argentina.

O governo republicano espanhol, mesmo sabendo das possibilidades de desenvolvimento de atividades do "quinta-colunismo" nas sedes das representações estrangeiras, respeitou o direito de asilo. A República espanhola preocupava-se com sua imagem frente aos países que o concediam, receando que incidentes envolvendo os asilados pudessem servir de justificativa para a determinação desses em romperem com o governo legalmente constituído. O asilo diplomático teve, a princípio, uma dimensão fundamentalmente humanitária, mas acabou se transformando, no decorrer da guerra, em um tema de interesse político.

Durante os três anos de conflito civil, cerca de sessenta pessoas buscaram refúgio junto à representação brasileira que, devido a este contingente de pessoas, foi obrigada a alugar a casa adjacente à sua sede. ${ }^{16}$ Alcebíades Peçanha omitiu do governo espanhol a existência de asilados na sede da representação brasileira, o que nos permite pensar na existência de interesses pessoais neste gesto. Tal atitude pode estar relacionada à proteção de sua secretária particular Nelly Vidal, acusada de envolver-se na adulteração e venda de passaportes brasileiros para aqueles que desejavam sair do território espanhol. ${ }^{17} \mathrm{~A}$ menção às irregularidades cometidas pela secretária de Peçanha é recorrente na documentação trocada entre o Itamaraty e Martins Ramos.

Javier Rubio, autor do trabalho mais detalhado sobre o asilo diplomático ocorrido durante o conflito civil, nas breves páginas em que analisou a atuação da Embaixada brasileira frente à questão, não se furtou em tecer severas críticas ao que considerou uma "modesta e censurável política

\footnotetext{
${ }^{15}$ Javier Rubio. Asilos y canjes durante la guerra civil española: aspectos humanitários de una contienda fratricida. Barcelona: Editorial Planeta, 1979, p.31-38.

${ }^{16}$ Despacho de Cyro de Freitas Valle em nome do ministro de Estado para Argeu Guimarães, encarregado de negócios em Madri. Rio de Janeiro, 01 abr. 1939. Missões Diplomáticas Brasileiras. Despachos enviados a Madri (1935-1941). Arquivo Histórico do Itamaraty/RJ.

${ }^{17}$ Ofício n. 56 (reservado) de Carlos da Silveira Martins Ramos, encarregado de negócios em Barcelona para Oswaldo Aranha, ministro das Relações Exteriores do Brasil. Barcelona, 24 jul. 1938. Lata 630, maço 9696. Arquivo Histórico do Itamaraty/RJ.
} 
de asilo". ${ }^{18}$ A análise da extensa documentação diplomática, cruzada com as informações obtidas neste importante trabalho acadêmico, nos leva a afirmar que a representação diplomática do Brasil desenvolveu uma atuação inexpressiva e incompetente na resolução do caso. A não entrega das listas de asilados pelo embaixador Peçanha à República espanhola é um dos fatores que contribuiu para agravar as tensões entre a Embaixada brasileira e 0 Ministério de estado espanhol.

O governo republicano espanhol mostrou-se surpreso com a notícia de que havia pessoas na condição de asilados junto à representação brasileira. Quando assumiu seu posto no início de 1938, Martins Ramos fez questão de evidenciar que considerava o silêncio mantido acerca da existência de asilados na missão brasileira um erro. Ao não enviar a lista de refugiados para o governo republicano espanhol, o Brasil foi excluído das negociações que possibilitaram a evacuação de asilados de outras embaixadas. ${ }^{19}$

A República espanhola sabia que o asilo em algumas embaixadas era decorrente do interesse de muitos diplomatas em conseguir benefícios financeiros. Muitos cidadãos só obtiveram o asilo mediante o pagamento de um "oneroso portazgo, un portazgo en general de tipo económico, pero otras veces de uma naturaleza aún más abusiva e indigna". ${ }^{20}$ No caso brasileiro, nenhum documento nos possibilita levantar a hipótese de que Alcebíades Peçanha tivesse recebido benefícios financeiros para manter pessoas asiladas na Embaixada. No entanto, não deixa de causar estranhamento o fato de que, na posição de decano do corpo diplomático, não tenha fornecido as listas ao governo republicano espanhol.

A questão dos asilados ficou ainda mais complexa quando Martins Ramos descobriu que junto ao "anexo" não havia somente "brasileiros", como a princípio havia afirmado Peçanha, mas também alguns militares e religiosos. Com a existência destes últimos, dificilmente o governo espanhol autorizaria a evacuação de todos os indivíduos. As observações realizadas por Ramos indicam que Oswaldo Aranha o orientou a negociar a evacuação dos asilados até a França e seu internamento no Brasil. A negação

\footnotetext{
18 Javier Rubio, op. cit., p.73.

19 Idem, p.73.

20 Idem, p.156.
} 
da República espanhola à proposta se daria pelo ocorrido com os refugiados em outras embaixadas que, ao serem autorizados a se dirigirem ao país vizinho, fugiram para as regiões sob poder dos rebeldes.

Martins Ramos defendia que a questão dos asilados denegria a imagem do Brasil que, corroborando com muitas irregularidades, acabava por desrespeitar o governo da Espanha. Também não se furtou em criticar a postura do próprio Itamaraty na condução da política externa brasileira diante da República espanhola. Para ele, o Brasil deveria agir de forma coerente com sua posição de país que, em nível diplomático, mantinha relações com aquele governo. O Itamaraty, sob liderança de Oswaldo Aranha, respondeu com rispidez às considerações do diplomata. A Secretaria de Estado das Relações Exteriores informou que o asilo era um procedimento tradicional do Brasil e que independentemente de comunicação oficial, o dever de Ramos era o de "proteger e salvar vidas", lembrando que isso era "o que seu antecessor soube fazer". A última menção, provavelmente, rebatia a crítica que Ramos teceu a atitude de Peçanha de não ter comunicado oficialmente ao governo espanhol a existência de asilados na representação brasileira. ${ }^{21}$

A existência de asilados na sede da Embaixada brasileira foi motivo de desconfianças do governo republicano para com a sinceridade das intenções do Brasil de "proteger cidadãos". Em agosto de 1938, o funcionário diplomático Luis Soroa relatou que em Madri, muitos cidadãos comportavam-se de forma a estar "num balneário ou numa colônia de férias", tomando banhos de sol e promovendo jogatinas em plena luz do dia. Informou que muitos possuíam armas e munições e se expunham diariamente dando vivas às evoluções dos aviões nacionalistas. ${ }^{22}$ Tais atitudes eram freqüentemente apontadas pelos jornais republicanos como prova da intenção das embaixadas estrangeiras em abrigar "fascistas". ${ }^{23}$

\footnotetext{
21 Telegrama da Secretaria de Relações Exteriores do Brasil para Embaixada do Brasil em Barcelona. Rio de Janeiro, 25 mar. 1938. Missões Diplomáticas Brasileiras. Telegramas enviados à Madrid (1938-1942). Arquivo Histórico do Itamaraty/RJ.

${ }^{22}$ Ofício de Luis de Soroa Garcia Goyena para Carlos da Silveira Martins Ramos, encarregado de negócios do Brasil em Barcelona. Madri, 22 ago. 1938. Lata 711, maço 10326. Arquivo Histórico do Itamaraty/RJ.

${ }^{23}$ Recorte do jornal Castilla Libre, de 16 ago. 1938. Anexo ao ofício de Luis de Soroa Garcia Goyena para encarregado de negócios, Carlos da Silveira Martins Ramos. Madri, 22 ago. 1938. Lata 711, maço 10326. Arquivo Histórico do Itamaraty/RJ.
} 
A posição do Itamaraty, em todo o período do conflito, foi de cautela, sempre ressaltando que o governo brasileiro não poderia tomar medidas que contrariassem o que havia sido ratificado nas conferências de Havana e Montevidéu sobre o direito de asilo. ${ }^{24}$ Ramos enfatizou que o caso espanhol não se ajustava minimamente aos princípios estabelecidos em tais conferências, lembrando que o asilo só era admissível para fornecer proteção temporária a um indivíduo ameaçado de efetivo e iminente perigo de vida. A aplicação ao caso em discussão não se justificava, uma vez que haviam sido dadas garantias de segurança aos que deixassem o "anexo". ${ }^{25}$

A atitude do governo brasileiro foi enviar à Legação em Berna uma ordem para solicitar junto ao governo suíço o auxílio da Cruz Vermelha. ${ }^{26}$ É provável que tal solicitação não tenha sido atendida por falta de tempo, uma vez que o conflito terminou poucos dias depois. Antes do término da guerra três dezenas de asilados abandonaram a representação brasileira. ${ }^{27}$ Provavelmente aqueles que se inseriam na categoria de militares e religiosos deixaram a sede da Embaixada do Brasil somente após os nacionalistas entrarem em Madri, o que culminou no fim do conflito.

Outra questão que gerou intensa troca de correspondência entre o Itamaraty e os diplomatas na Espanha foi a repatriação de cidadãos que possuíam dupla cidadania. No Brasil, há prevalência do reconhecimento da nacionalidade pelo local de nascimento, o jus solis, cuja palavra indica o direito de solo. ${ }^{28}$ Os filhos de imigrantes espanhóis nascidos no Brasil, além de brasileiros por este princípio, eram considerados cidadãos espanhóis, uma vez que a Espanha segue o jus sanguinis, reconhecendo a nacionalidade daqueles que tem ascendência espanhola. Tal diferença no reconhecimento da

\footnotetext{
24 Referências à Convenção sobre Asilo assinada na VI Conferência Pan-americana de Havana, em 1928, e à Convenção sobre asilo político, assinada na VII Conferência Internacional Americana de Montevidéu, em 1933. Ver: Luiz Paulo Teles F. Barreto. "Das diferenças entre os institutos jurídicos do asilo e do refúgio". Disponível em: http://www.mj.gov.br/snj/artigo refugio.htm. Acesso em 31 mar. 2007.

${ }^{25}$ Ofício de Carlos da Silveira Martins Ramos, encarregado de negócios do Brasil na Espanha para Oswaldo Aranha, ministro das Relações Exteriores do Brasil. Barcelona, 23 ago. 1938. Lata 711, maço 10326. Arquivo Histórico do Itamaraty/RJ.

${ }^{26}$ Telegrama da Secretaria das Relações Exteriores para Legação do Brasil em Berna. Rio de Janeiro, 06 mar. 1939. Lata 293, maço 10326. Arquivo Histórico do Itamaraty/RJ.

${ }_{27}$ Javier Rubio, op. cit., p.76.

28 José Francisco Rezek. Direito Internacional público: curso elementar. São Paulo: Saraiva, 1995, p.185-190.
} 
nacionalidade gerou inúmeros casos curiosos, de filhos de espanhóis que obtiveram do governo espanhol e das sociedades de repatriação auxílio para se repatriarem a Espanha, e que anos depois solicitavam junto aos consulados brasileiros auxílio para, na condição de brasileiros, serem novamente repatriados ao Brasil.

Durante a Guerra Civil Espanhola a quantidade de pessoas que buscaram os consulados brasileiros e a Embaixada em Madri para solicitar repatriação cresceu vertiginosamente. Os espanhóis que possuíam dupla cidadania podiam com maiores facilidades pleitear o asilo nas missões diplomáticas dos países que adotavam o jus solis, assim como garantir passaporte estrangeiro para a saída do território espanhol. No contexto da guerra, esta era uma das melhores condições que alguém podia aspirar.

O número de solicitações de repatriação chegou a preocupar o Ministério das Relações Exteriores, que solicitou um parecer de consultores na área de direito. Em um memorandum do Itamaraty, destinado ao chefe da divisão política e diplomática, o relator sugeriu que o Ministério da Justiça revisse a legislação sobre a dupla cidadania para evitar que o Brasil desse guarida a "oportunistas" que só queriam ser repatriados para "fugir ao alistamento militar". ${ }^{29}$ Diversos diplomatas mostraram sua indignação diante do que consideravam "complascência" das leis brasileiras frente aos abusos cometidos por tais cidadãos. De acordo com esta visão, os jovens que solicitavam repatriação ou simplesmente documentos que pudessem livrá-los das fileiras do exército não atendiam a um requisito determinante: o sentimento de amor à pátria. ${ }^{30} \mathrm{O}$ discurso dos diplomatas revela a exaltação da nacionalidade, vista como um valor "sagrado" que não poderia ser atribuída àqueles que não estivessem integrados à sociedade brasileira.

Mesmo após o término do conflito, os consulados e a Embaixada continuaram a receber o pedido de auxílio de muitos espanhóis que sofriam com a "institucionalização da vingança franquista" contra os ex-combatentes

\footnotetext{
${ }^{29}$ Memorandum (ass. Ilegível) para o chefe da divisão política e diplomática. Ministério das Relações Exteriores. Rio de Janeiro, 16 jan. 1939. Lata 716, maço 10364. Arquivo Histórico do Itamaraty/RJ.

${ }^{30}$ Idem.
} 
republicanos. ${ }^{31}$ Diante dessa realidade, entre 1939 e 1940, a quantidade de pedidos de repatriação junto às representações brasileiras continuou elevandose. A proteção consular do Brasil era a saída encontrada por centenas de espanhóis que haviam lutado em defesa do regime republicano e que temiam as represálias do governo franquista.

O Itamaraty preocupou-se com a repatriação dos brasileiros que lutaram a favor dos republicanos como voluntários através das Brigadas Internacionais. Sabemos, no entanto, que a maioria deles estava condenada por atividades comunistas e, portanto, impossibilitada de retornar ao Brasil. ${ }^{32} \mathrm{O}$ setor consular do Itamaraty observou que a repatriação de tais brasileiros era improcedente e que já havia avisado a Embaixada de que estes indivíduos haviam perdido a nacionalidade brasileira, de acordo com o artigo 2 do Decreto-Lei n. 389 de abril de $1938 .{ }^{33}$ Tal artigo previa que perderia a nacionalidade o brasileiro que realizasse a prestação voluntária do serviço militar em outro país. ${ }^{34}$

A legislação de caráter nacionalista possibilitou uma interpretação deturpada da condição dos brigadistas, pois era de conhecimento público que as Brigadas Internacionais constituíram-se como um corpo independente da organização do Exército republicano espanhol. Ao se incorporarem às Brigadas, os estrangeiros não estavam servindo militarmente o governo de outro país. A perda de nacionalidade respaldada pelo artigo do decreto mencionado acima não foi sustentada, mas tal alegação demonstra o quanto se tornava difícil, naquele contexto, a autorização para que os brigadistas pudessem retornar ao Brasil.

Embora a ação externa do Itamaraty para a Espanha estivesse respaldada pelas diretrizes de Oswaldo Aranha, havia uma corrente dentro do Ministério e dos círculos de poder que desejavam o reconhecimento dos nacionalistas espanhóis ainda em 1938, portanto, meses antes do término do

${ }^{31}$ Paul Preston. La Guerra Civil. Las fotos que hicieron historia. Esfera de los libros: $\mathrm{J}$ de J Editores, 2005, p.9.

${ }^{32}$ Sobre a repressão da polícia política aos brigadistas brasileiros ver: Ismara Izepe de Souza. República Espanhola, op. cit.

${ }^{33}$ Memorandum do chefe da Divisão Consular (ass. ileg.) para Secretário Geral das Relações Exteriores. Rio de Janeiro, 06 abr. 1940. Lata 1756, maço 35635. Arquivo Histórico do Itamaraty/RJ.

${ }^{34}$ Artigo 2, letra b do Decreto-Lei n. 389 de 25 de abril de 1938. 
conflito. Ao final de 1938, o Ministério das Relações Exteriores comunicou à Embaixada brasileira em Barcelona a intenção de acreditar junto ao governo de Franco um agente oficial, a exemplo do que realizavam outros países. ${ }^{35}$

Em março de 1939, após o reconhecimento dos demais países europeus e dos Estados Unidos, o governo brasileiro reconheceu o governo franquista. Tal decisão, tomada somente a partir da certeza de que a vitória nacionalista seria efetiva em pouco tempo, nos leva a refletir sobre as relações entre a nossa política externa e os interesses da política externa dos EUA.

A pseudo "neutralidade" adotada pelo governo Vargas diante da guerra civil da Espanha pode ser interpretada como uma medida de alinhamento à política externa norte-americana, que neste momento, pregava a não intervenção nos assuntos exteriores. Desde o início do conflito, Oswaldo Aranha vinha atuando junto a Getúlio Vargas, com vistas a impedir que o Brasil se envolvesse com os problemas políticos europeus, argumentando que 0 reconhecimento do governo de Franco implicaria numa aproximação estreita com a Alemanha nazista. ${ }^{36}$ Mas tal postura não pode ser vista apenas como reflexo automático das decisões do centro hegemônico norte-americano, uma vez que o Brasil habilmente começava a ampliar sua margem de autonomia, ao explorar "as indefinições do jogo hegemônico mundial entre Alemanha e Estados Unidos". ${ }^{37}$

Getúlio Vargas e Oswaldo Aranha optaram por promover a manutenção de uma "neutralidade" descomprometida com a coerência de evitar uma imagem negativa da República espanhola em âmbito interno. Neste sentido, a postura brasileira pode ser considerada dúbia. Oficialmente, mantinham-se as relações diplomáticas com o governo republicano, mas através de ações oficiosas, o governo brasileiro procurava favorecer o lado rebelde, o que se comprovou com o envio sigiloso de café aos franquistas. $O$ "secretismo" de tal doação combinava com uma série de outras iniciativas do

\footnotetext{
35 Telegrama da Secretaria de Estado das Relações Exteriores à Embaixada do Brasil em Barcelona. Rio de Janeiro, 10 dez. 1938. Missões Diplomáticas Brasileiras. Telegramas expedidos a Madri (1938-1942). Arquivo Histórico do Itamaraty/RJ.

36 Eliane Ávila Silveira. A Guerra Civil Espanhola e as elites políticas brasileiras: 1936-1939. Dissertação de Mestrado em História. Porto Alegre: PUC, 1991, p. 147.

${ }_{37}$ Gerson Moura. Autonomia na dependência: a política externa brasileira de 1935 a 1942. Rio de Janeiro: Nova Fronteira, 1980, p.14.
} 
Estado Novo que, sem ser dúbio nos bastidores do poder, atendia as preferências das elites políticas brasileiras pelos nacionalistas espanhóis. 